\title{
Métodos de assepsia na multiplicação in vitro da bananeira 'Pacovan' (Musa spp.)
}

\author{
Methods in the in vitro multiplication of 'Pacovan' banana (Musa spp.) \\ Métodos de asepsia en la multiplicación in vitro de banano 'Pacovan' (Musa spp.)
}

\author{
Michael Raphael Soares Vieira \\ ORCID: https://orcid.org/0000-0002-1436-8936 \\ Universidade Federal do Amazonas, Brasil \\ E-mail: michael.soares.vieira@gmail.com \\ Eneida Guerra Silvestrim \\ ORCID: https://orcid.org/0000-0001-8392-1486 \\ Universidade Federal do Amazonas, Brasil \\ E-mail: egsilvestrim@gmail.com \\ Arlindo Almeida De Lima Filho \\ ORCID: https://orcid.org/0000-0003-0754-0723 \\ Instituto de Pós-graduação e Graduação, Brasil \\ E-mail: arlindo.almeida.filho@gmail.com \\ Aixa Braga Lopes \\ ORCID: https://orcid.org/0000-0002-4680-6814 \\ Instituto Nacional de Pesquisas da Amazônia, Brasil \\ E-mail: lopesaixa@gmail.com \\ Fernanda Guerra Silvestrim \\ ORCID: https://orcid.org/0000-0002-7571-9795 \\ Faculdade Estácio do Amazonas, Brasil \\ E-mail: ca.ecologica@gmail.com
}

\begin{abstract}
Resumo
A cultivo da banana 'Pacovan' ainda é realizada operando com métodos tradicionais no estado do Amazonas, onde ainda existem registros de produção da fruta com doenças causadas por fungos e por bactérias. Porém, outros métodos de propagação, como a micropropagação in vitro, podem ser desenvolvidos e aperfeiçoados, para que ocorra a elevação da taxa de multiplicação em curto espaço de tempo além de aperfeiçoar, significantemente, a taxa de qualidade da produção de mudas. Entretanto, os índices de contaminação ainda são um dos maiores problemas desta técnica. Este trabalho teve por objetivo avaliar o melhoramento no processo de assepsia analisando diferentes tipos de concentrações de álcool, hipoclorito de sódio e Tween 20 e diferentes variações de tempo, durante o processo de assepsia do explante meristemático, visando identificar o processo mais eficiente de descontaminação. O experimento foi planejado em delineamento experimental inteiramente casualizado para a análise de regressão linear, onde foram constituídos por três tratamentos e vinte repetições, sendo cada repetição representada por cinco explantes em diferentes experimentos. Os dados foram submetidos à análise de variância (ANOVA), seguido de testes de média Tukey $5 \%$ de probabilidade. Os resultados permitiram concluir que, com elevado tempo do explante submerso no hipoclorito de sódio há eficácia contra fungos e bactérias. Porém, elevadas concentrações de $\mathrm{NaClO}$ leva à toxicidade devido à alta oxidação. Pois, por ser um agente oxidante, altas concentrações se tornam tóxicas aos explantes. Nos experimentos, o menor índice de contaminação dos tratamentos testados foi o E3, permitindo o desenvolvimento normal dos explantes e possibilitando que seja utilizado para o controle de contaminações na micropropagação de banana 'Pacovan' in vitro.
\end{abstract}

Palavra-chave: Oxidação; Fungos; Bactérias.

\begin{abstract}
The cultivation of 'Pacovan' banana is still carried out using traditional methods in the state of Amazonas, where there are still records of fruit production with diseases caused by fungi and bacteria. However, other propagation methods, such as in vitro micropropagation, can be developed and improved, so that the multiplication rate can be increased in a short period of time, in addition to significantly improving the quality rate of seedling production. However, contamination rates are still one of the biggest problems with this technique. This work aimed to evaluate the improvement in the asepsis process by analyzing different types of concentrations of alcohol, sodium hypochlorite and Tween 20 and different time variations during the asepsis process of the meristematic explant, in order to identify the most efficient decontamination process. The experiment was planned in a completely randomized experimental design for linear regression analysis, where they were constituted by three treatments and twenty repetitions, with each repetition represented by five explants in different experiments. Data were subjected to analysis of variance
\end{abstract}


(ANOVA), followed by Tukey $5 \%$ probability mean tests. The results allowed us to conclude that, with a long explant time submerged in sodium hypochlorite, there is efficacy against fungi and bacteria. However, high concentrations of $\mathrm{NaClO}$ lead to toxicity due to high oxidation. As it is an oxidizing agent, high concentrations become toxic to explants. In the experiments, the lowest level of contamination of the treatments tested was E3, allowing the normal development of the explants and allowing it to be used to control contamination in the micropropagation of 'Pacovan' banana in vitro.

Keyword: Oxidation; Fungi; Bacteria.

\begin{abstract}
Resumen
El cultivo del banano 'Pacovan' todavía se realiza con métodos tradicionales en el estado de Amazonas, donde aún existen registros de producción de frutos con enfermedades causadas por hongos y bacterias. Sin embargo, se pueden desarrollar y mejorar otros métodos de propagación, como la micropropagación in vitro, de modo que la tasa de multiplicación se pueda incrementar en un corto período de tiempo, además de mejorar significativamente la tasa de calidad de la producción de plántulas. Sin embargo, las tasas de contaminación siguen siendo uno de los mayores problemas de esta técnica. Este trabajo tuvo como objetivo evaluar la mejora en el proceso de asepsia mediante el análisis de diferentes tipos de concentraciones de alcohol, hipoclorito de sodio y Tween 20 y diferentes variaciones de tiempo durante el proceso de asepsia del explante meristemático, con el fin de identificar el proceso de descontaminación más eficiente. El experimento fue planeado en un diseño experimental completamente al azar para análisis de regresión lineal, donde estuvieron constituidos por tres tratamientos y veinte repeticiones, con cada repetición representada por cinco explantes en diferentes experimentos. Los datos se sometieron a análisis de varianza (ANOVA), seguido de pruebas de media de probabilidad del 5\% de Tukey. Los resultados permitieron concluir que, con un tiempo de explante prolongado sumergido en hipoclorito de sodio, existe eficacia frente a hongos y bacterias. Sin embargo, las altas concentraciones de $\mathrm{NaClO}$ provocan toxicidad debido a la alta oxidación. Como es un agente oxidante, altas concentraciones se vuelven tóxicas para los explantes. En los experimentos, el nivel más bajo de contaminación de los tratamientos probados fue el E3, permitiendo el normal desarrollo de los explantes y permitiendo su uso para controlar la contaminación en la micropropagación del banano 'Pacovan' in vitro.
\end{abstract}

Palabra clave: Oxidación; Hongos; Bacterias.

\title{
1. Introdução
}

A banana é considerada a fruta de maior consumo no mundo. Possui grande aceitação comercial e é produzida em maior quantidade nos países tropicais. A banana 'Pacovan' (Musa spp) vem se destacando, pois possui diversidade em seu consumo, podendo ser processada para a agroindústria, com a possibilidade de obtenção de diferentes tipos de produtos (Borges, 2004; Hermínio et al., 2015; Barbosa et al., 2019). A espécie está presente no hábito alimentar da população amazonense. A fruta possui boa fonte de energia e minerais como o potássio e manganês, que são intensificadas no processo de fritura para a sua comercialização (Aguiar, 2000; Silva, 2015; Gasparotto et al., 2019).

Da produção mundial de banana, o Brasil produziu apenas aproximadamente 9,5\%. Foram exportados apenas de 1 a $2 \%$ da produção interna do Brasil, apesar de ser o segundo país com maior produção da fruta. O Amazonas não se encontra na lista dos estados produtores, porém, o cultivo da banana em sistema agroflorestal, certamente será uma boa opção para a região amazônica, podendo assim caracterizar o estado com um potencial elevado para a produção desta cultura. A média de valor de produção brasileira nos últimos cinco anos foi de R\$ 7.836.578,20 (Borges, 2004; IBGE, 2021).

A produção de banana no Brasil é de aproximadamente 6 toneladas, com rendimento médio $14.361 \mathrm{~kg} / \mathrm{ha}$, mantendo a média de produção. De fato, o Brasil possui uma vasta variedade de bananas. Para os agricultores, são consideradas para produção as espécies de alta produtividade, que sejam tolerantes, pois doenças e pragas são problemas muito sérios nesta cultura, ocasionando perdas que chegam a $100 \%$ da produção e doenças como o Mal-do-Panamá (Fusariumspp), a Sigatokaamarela (Mycosphaerellamusicola) e o moko (Ralstoniasolanacearum) são os principais problemas do cultivo (Flori \& Resende, 2016; Sebrae, 2016).

Outras características procuradas nas bananeiras são a resistência a secas e ao frio. Logo, podem-se identificar poucas cultivares com boa expectativa para exploração comercial. Um dos fatores que influenciam a produção e o crescimento das 
bananeiras está relacionada com a sua variação genética, de variedades mais resistentes a patógenos em geral, especialmente a utilização de mudas saudáveis e resistentes a doenças fúngicas e/ou bacterianas (Borges e Souza 2004; Bavaresco, et al., 2017).

A cultivar 'Pacovan', segundo Rodrigo Filho et al. (2014), não agrupa todas as características mencionadas, é vista no cenário nacional como uma das mais disseminadas por ser rústica e ter alta aceitação dos consumidores. Em virtude disso, se torna a melhor opção para os produtores das regiões norte e nordeste do país, onde o cultivo é feito com baixos recursos tecnológicos. Assim, é necessário que sejam criadas metodologias simples para o processo de multiplicação em larga escala da banana 'Pacovan', que permita que o agricultor obtenha uma produção de alta qualidade e com boa produtividade, visando o atendimento da demanda e consumo do estado e viabilidade econômica com o crescimento da exportação.

O processo de propagação tradicional possui características consideradas indesejadas, uma vez que estas favorecem a propagação de doenças e pragas, o processo fica sujeito à sazonalidade e baixa taxa de multiplicação (da Silva et al., 2019). A multiplicação por clonagem in vitro surge para se obter organismos vegetais que possuam características consideradas superiores às já existentes no mercado, além de possibilitar a produção de maior quantidade de mudas idênticas à planta mãe, em períodos relativamente curtos (Pedrotti et al., 2017; Mezzalira \& Kuhn, 2021), utilizando-se o meio de cultura neste processo, pois possui macro e micronutrientes considerados essenciais para o desenvolvimento (Fernandes, 2016; Machado \& Zamarian, 2020; Matos et al., 2020).

O processo de micropropagação envolve pequenas quantidades de fragmentos do tecido vivo da cultura, conhecidos por explantes, que possuem células meristemáticas. Após sua retirada faz-se necessária a desinfecção por um processo de assepsia que pode variar de método conforme o tipo de cultura. Para que ocorra sucesso na técnica de micropropagação e posterior estabelecimento in vitro, o protocolo adotado na assepsia deve acarretar em maior taxa de sobrevivência dos explantes para seguir para as próximas etapas (Fernandes \& Costa, 2011).

A etapa de assepsia é uma das principais dificuldades encontradas no processo de micropropagação, quando não possui um protocolo ou método pré-disposto para obtenção de uma quantidade suficiente de culturas assépticas, permitindo assim, a continuidade para o estabelecimento in vitro. Esta contaminação se dá pela presença de microorganismos no explante ou na ineficiência da desinfecção superficial. (Golle et al., 2013),

Portanto, o processo de assepsia é uma das principais etapas para um eficaz estabelecimento dos explantes in vitro, para que as demais etapas obtenham sucesso (Effegem et al., 2014; da Silva et al., 2019).

Diante da problemática, este estudo tem como objetivo geral identificar métodos eficientes para o processo de assepsia para a multiplicação in vitro de material genético selecionado da bananeira 'Pacovan' (Musa spp). A multiplicação de clones, que aliem produtividade e resistência às doenças, contribuirá para o aumento das áreas de plantios e diminuição de uso de defensivos agrícolas, visando a redução dos custos e melhoramento da qualidade da fruta, além de mitigações de danos ao meio ambiente.

\section{Metodologia}

O experimento foi conduzido no Laboratório de cultura de tecido do Instituto Nacional de Pesquisa da Amazônia INPA. As estruturas propagativas da bananeira foram retiradas de plantas saudáveis/isoladas da Estação Experimental de Fruticultura - INPA (Figura 1). 
Figura 1: A - Bananeiras da Estação Experimental do INPA / B - Explantes meristemáticos.

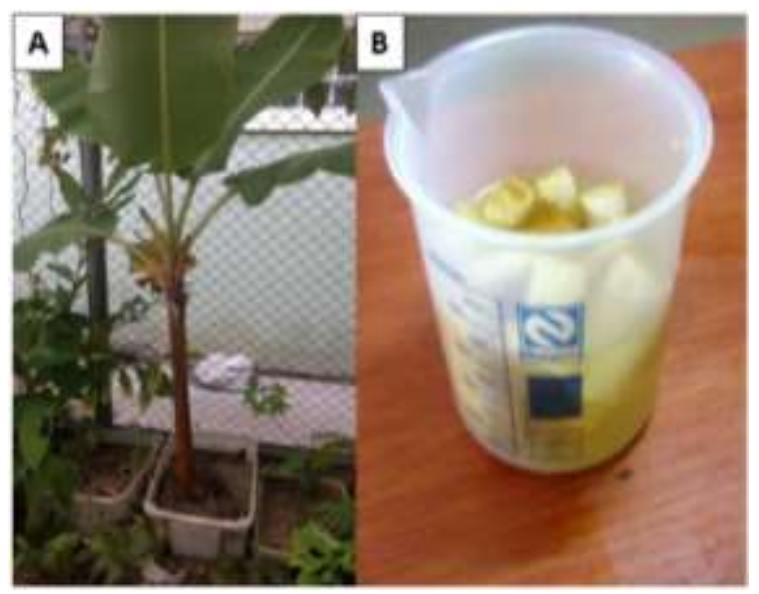

Fonte: Acervo dos autores.

Inicialmente, foi feita a seleção das amostras, extraindo os explantes com comprimento médio de 6 cm de diâmetro da parte do caule subterrâneo chamada rizoma, onde ocorre a reprodução vegetativa, por possuir células meristemáticas (figura 02). Os tratamentos para estabelecer o experimento seguiram a seguinte ordem:

E1: Lavar o explante retirado com $5 \mathrm{~cm}$ de circunferência, com água corrente para retirada do solo. Em seguida, preparar o fluxo laminar para o tratamento. Com auxílio de pinça e bisturi (Figura 2), reduzir o explante a uma circunferência de $3 \mathrm{~cm}$ e depositar sequencialmente em um becker com álcool 90\% por 60 segundos e em seguida, depositar em solução com hipoclorito de sódio comercial a 2\% por $20 \mathrm{~min}$, com 3 gota de Tween 20 para $11 \mathrm{ml}$ de solução;

Figura 2: Fluxo Laminar preparado para a assepsia.

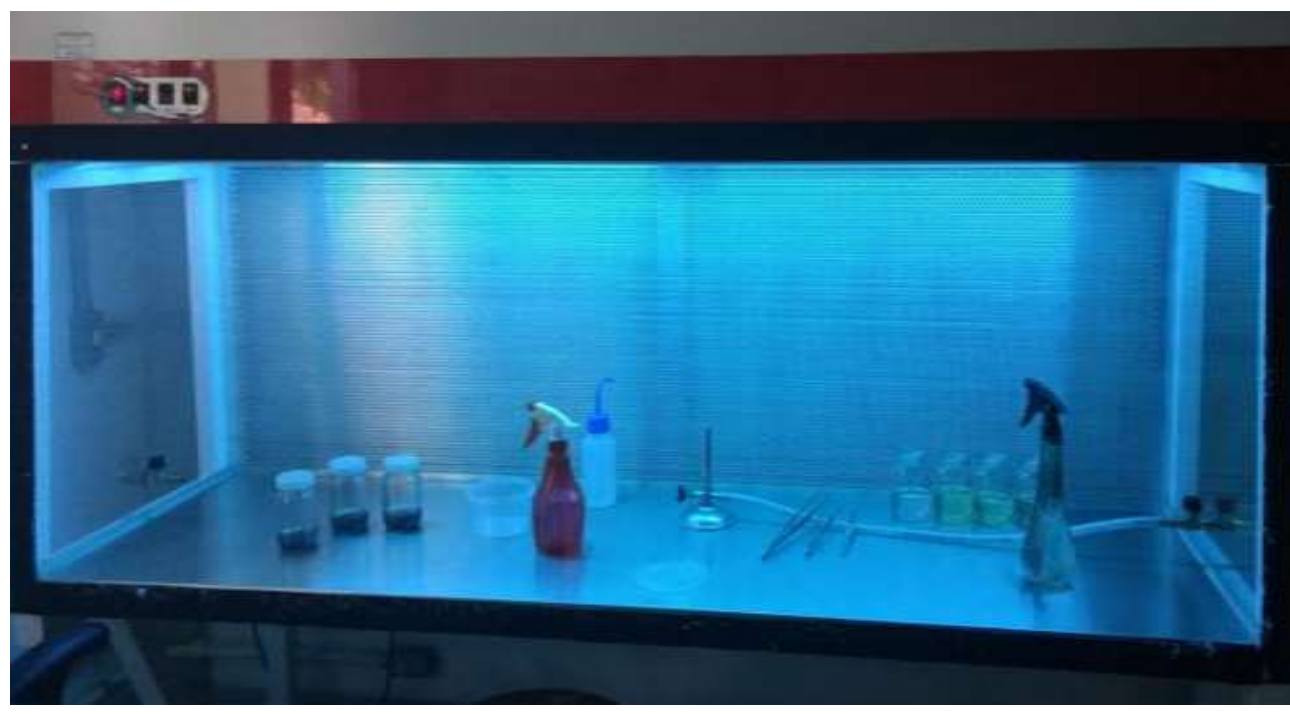

Fonte: Acervo dos autores.

E2: Lavar o explante retirado com tamanho de $6 \mathrm{~cm}$ de circunferência, com água corrente para retirada do solo. Em seguida, fazer a assepsia externa com hipoclorito de sódio comercial a $2 \%$ por 20 min, antes de ir para o fluxo laminar para o tratamento. Com auxílio de pinça e bisturi, reduzir o explante a uma circunferência de $3 \mathrm{~cm}$, depositar sequencialmente em um becker com álcool $70 \%$ por 60 segundos e posteriormente, depositar em solução com hipoclorito de sódio comercial a $2 \%$ por 30 min, com 2 gotas de Tween 20 para $11 \mathrm{ml}$ de solução; 
E3: Lavar o explante retirado com tamanho de $7 \mathrm{~cm}$ de circunferência, com água corrente para retirada do solo. Em seguida, fazer assepsia externa com 30 segundos de álcool 70\% e $10 \mathrm{~min}$ de hipoclorito de sódio comercial a 2\%, antes de ir para o fluxo laminar para o tratamento. Com auxílio de pinça e bisturi, reduzir o explante a uma circunferência de $2 \mathrm{~cm}$, depositar sequencialmente em um becker com álcool $70 \%$ por 60 segundos e posteriormente, com hipoclorito de sódio comercial a $2 \%$ por 20 min com 1 gota de Tween 20 para $30 \mathrm{ml}$ de solução. Importante salientar que no E3, a cada procedimento foi feita a limpeza dos explantes, sempre intercalando tríplice lavagem com água estéril deionizada, destilada.

O experimento foi planejado em delineamento experimental inteiramente casualizado (Figura 3) e a análise de regressão linear, onde foram constituídas por três tratamentos e vinte repetições, sendo cada repetição representada por cinco explantes em diferentes experimentos. Os dados foram submetidos à análise de variância (ANOVA), seguido de testes de média Tukey $5 \%$ de probabilidade.

Figura 3: Experimentos em DIC após assepsia.

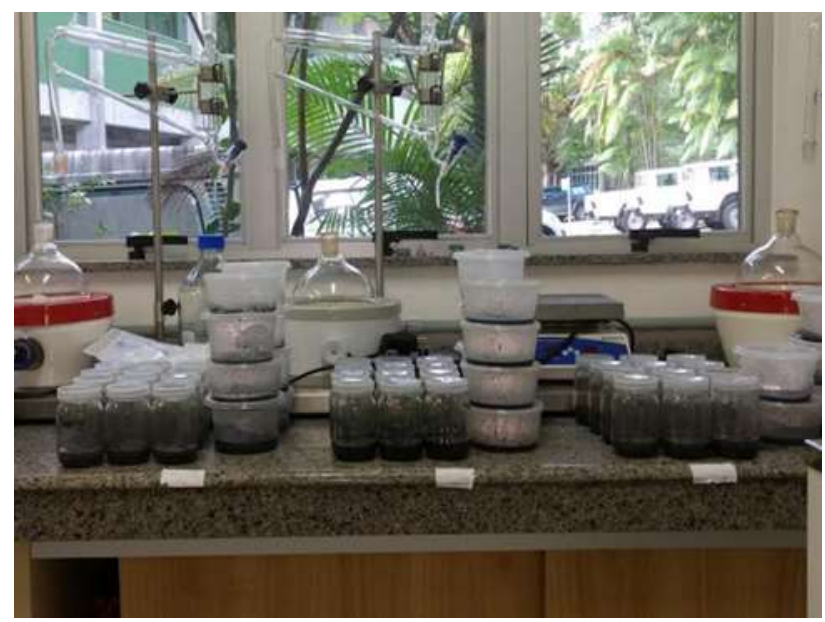

Fonte: Acervo dos autores.

Depois da retirada do fluxo laminar, todos os experimentos foram submetidos à incubação em vidraria laboratorial (Figura 4), sendo mantidos em ambiente escuro durante 7 dias, em um compartimento de polietileno. A inoculação foi feita em meio de cultura MS Murashige e Skoog (1962), sólido (2,3 g.L.-1 de Phytagel), suplementado com vitaminas de MS, sacarose $\left(20,0\right.$ g.L $\left.\mathrm{L}^{-1}\right)$, benziladenina $\left(2,5 \mathrm{mg} \cdot \mathrm{L}^{-1}\right)$, o pH foi ajustado para 5,8 e a incubação acorreu com temperatura de $25 \pm 2{ }^{\circ} \mathrm{C}$ e Fotoperiodo de 16h, a uma intensidade luminosa de $30 \mu \mathrm{mol} \mathrm{m} \mathrm{m}^{-2} \mathrm{~s}^{-1}$, com lâmpadas fluorescentes, conforme descrito em literatura especializada (Borges, 2004). Além de reguladores de crescimento utilizados, foram adicionadas misturas complexas com 150 ml.L-1 de água de coco e 3g.L.-1decarvãoativado (Rondon et al., 2019; Machado \& Zamarian, 2020).

Figura 4: Experimentos em DIC após assepsia.

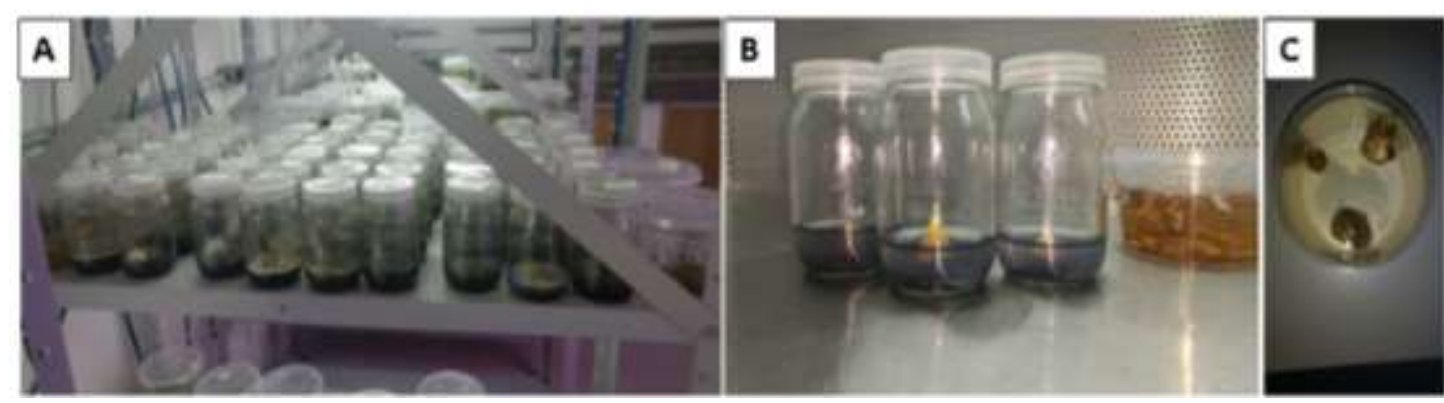

Fonte: Acervo dos autores. 


\section{Resultados e Discussão}

Os resultados para a assepsia demonstram que, de acordo com as análises de variância, os experimentos utilizando hipoclorito de sódio, em diferentes variações de tempo para assepsia dos explantes, resultaram em diferença significativa para os resultados avaliados sete dias após a assepsia. Verificou-se que o experimento com cloro ativo a $2 \%$ com maior eficiência, foi E3 que reduziu, em até 39\%, a contaminação (Quadro 1);

Quadro 1: Índices de contaminação de 300 experimentos.

\begin{tabular}{|c|c|c|c|c|c|c|c|c|c|c|c|}
\hline \multicolumn{4}{|c|}{ E1 } & \multicolumn{4}{|c|}{ E2 } & \multicolumn{4}{|c|}{ E3 } \\
\hline Oxidação & Bactéria & Fungos & CONT. & Oxidação & Bactéria & Fungos & CONT. & Oxidação & Bactéria & Fungos & CONT. \\
\hline $13 \%$ & $36 \%$ & $41 \%$ & $90 \%$ & $44 \%$ & $27 \%$ & $11 \%$ & $82 \%$ & $27 \%$ & $18 \%$ & $6 \%$ & $51 \%$ \\
\hline
\end{tabular}

Fonte: Autores (2021).

O E1, com 90\% de contaminação indica que pouco tempo do explante imerso no hipoclorito de sódio, impossibilita a continuidade do processo de micropropagação. Já em E2, observou-se que 44\% de contaminação foi exclusivamente de oxidação, índices relativamente altos comparados com os outros experimentos, ou seja, muito tempo do explante submerso no hipoclorito de sódio, apesar de eficiente na diminuição de contaminação de fungos e bactérias, acabam por oxidar o explante, impossibilitando a continuidade para a multiplicação do mesmo. Para o controle de fungo e bactéria, a redução significativa de contaminações pode ser observada no E3, obtendo-se uma queda de 53\% de contaminação, comparando com o E1. No experimento E3, contaminaram-se 51\% das amostras, sendo que, para o E1, houve $90 \%$ de contaminação, este resultado pode ser derivado de manuseio laboratorial ou fungos endofíticos na própria superfície rugosa do material vegetal.

Analisando a oxidação, identificou-se que o E1 foi o menor valor de oxidação e E3 não apresentou diminuição em relação ao E1 e E2. Porém, sem provocar a perda dos explantes que foram analisados posteriormente aos experimentos. Os resultados obtidos, evidenciam os dados de Muniz (2013), que usou o hipoclorito de sódio como descontaminante para o tomate-de-capucho (Physalis peruviana) e cereja de inverno (Physalis alkekengi), comprovando a eficácia ao combate de contaminações fúngicas e principalmente por bactérias, concordando com seu resultado.

Na pesquisa sobre assepsia de segmentos nodais de mini-rosa (Rosa sp.) para o estabelecimento in vitro da Silva et al. (2019), identificou que, os segmentos nodais submetidos ao hipoclorito de sódio em uma concentração de 1,25\%, pelo tempo de 30 minutos de imersão, apresentaram maior percentual de assepsia sem danos no estabelecimento in vitro. Em contrapartida, o trabalho de Mezzalira e Kuhn (2021), sobre assepsia de segmentos nodais de Phalaenopsis, não conseguiu estabelecer um protocolo eficiente de assepsia.

Em todos os estágios do experimento ocorreram perdas causadas pelos três fatores, oxidação, contaminação por fungos e contaminação por bactérias. A diferença foi observada logo após a transferência dos explantes do escuro para o ambiente com luminosidade, onde verificou-se a ocorrência de maior frequência de fungos e bactérias no experimento E1, enquanto o experimento E2 apresentou maior quantidade de oxidação em $44 \%$ dos casos, diminuindo consideravelmente os índices de bactérias e fungos, exceto em situações de bactérias endógenas que, no experimento 02, houve contaminação após o desenvolvimento do explante. Tendo em vista a elevada exposição do explante no E3, para uma assepsia dupla, optou-se pela elevação do tamanho dos explantes em sua extração, intensificando assim a oxidação das camadas externas dos explantes e somente no fluxo laminar foi ajustado o tamanho de inoculação dos explantes, em média de $3 \mathrm{~cm}$ de circunferência. 
O E3 adotou maior tempo de atuação de limpeza no fluxo laminar, executando todos os passos com lavagens constantes do explantes, utilizando lavagem com água estéril deionizada, destilada e autoclavada, processo esse que acarretou a diminuição de contaminação em até $40 \%$.

$\mathrm{Na}$ Figura 5-A, que trata da contaminação por bactéria, pode-se observar que o E3 apresentou maior intervalo interquartil e com maior quantitativo de experimentos abaixo da mediana, estando os dados agrupados no Q1, a análise de estatística da anova para bactérias apresentou significância em 0.00039. Logo, seguimos para o post hock - Tukey, onde identificou-se que o E2 apresentou tanto similaridade com o E1, quanto com o E3, já os experimentos E1 e E3 apresentaram maior divergência nos dados.

Figura 5: Box-Plot comparativo entre os experimentos por contaminação por bactéria (A), Contaminação por fungos (B) e contaminação por oxidação (C).

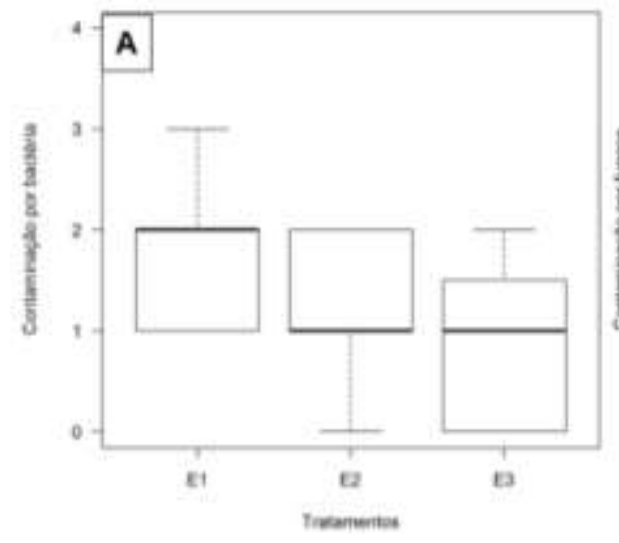

Para dos dados de Contaminação por fungos (Figura 5-B), o intervalo interquartil que apresentou menor dispersão foi

o E3. Com isso apresentou um outlier, podendo ser atribuído a uma contaminação por manuseio inadequado na assepsia. Já a tendência central mais elevada foi o E1, apresentando maiores índices de contaminação por fungos, com todos os dados acima da mediana e estando dispostos no $3^{\circ}$ quartil.

No que se refere à contaminação por oxidação das amostras (Figura 5-C), o E2 apresentou maior quantitativo de dados acima da mediana, podendo ser atribuído à dupla assepsia por hipoclorito de sódio, acarretando maior contaminação por oxidação. 
Figura 6: Box-Plot comparativo entre os experimentos por contaminação total.

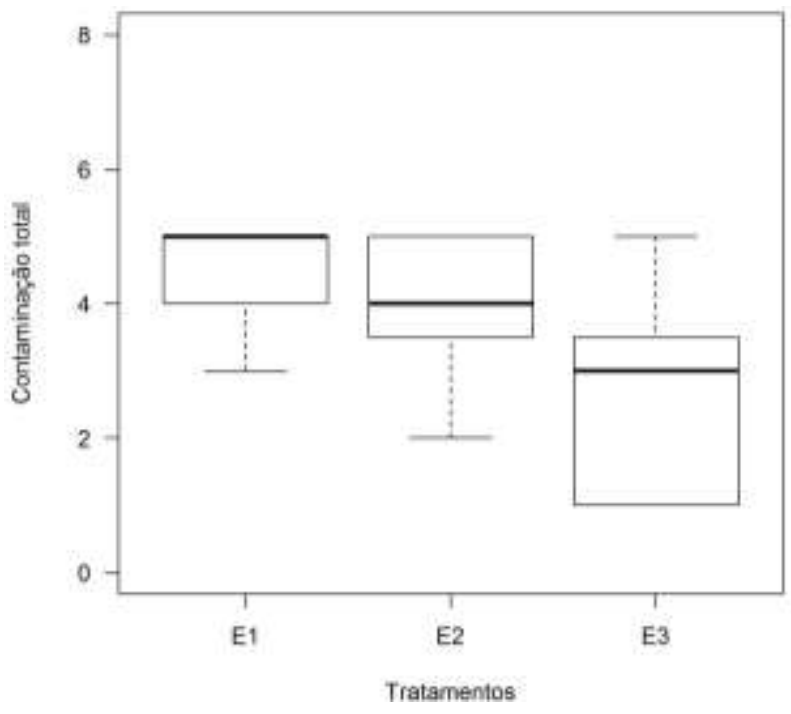

Fonte: Autores (2021).

Quando realizado o agrupamento dos dados para uma análise de contaminação total (figura 6), podemos observar que a tendência central com maior valor da mediana é o E1 e, apesar dos dados do E3 estarem em maior disposição no Q1, a mediana ainda se apresentou acima de 3.

Batista et al. (2019) apresentou um protocolo eficiente para o cultivo in vitro desta espécie Euterpe precatoria MART na qual, os menores índices de contaminação e oxidação se deram em tratamento com hipoclorito a $2 \%$ em um tempo de 20 minutos no meio de cultura B\&G. Já Martínez et al. (2016), apresentou resultados satisfatórios com o uso de hipoclorito de sódio a 2,5\% em um tempo de 20 minutos, apresentando menores taxas de contaminação e elevadas taxas de germinação das sementes de mandacaru sem espinho.

\section{Considerações Finais}

Utilizando-se hipoclorito de sódio de cloro ativo a $2 \%$ por 30 minutos, reduz-se a contaminação por bactérias e fungos em explantes de banana 'Pacovan', possibilitando seu desenvolvimento para posterior multiplicação in vitro.

Apesar do hipoclorito de sódio e o álcool a 70\% mostrarem eficácia no tratamento contra fungos e bactérias, quanto maior o tempo de imersão, maior a oxidação dos explantes, podendo ocasionar a perda dos mesmos.

Sugere-se, a partir desta pesquisa, que trabalhos futuros sejam realizados visando uma padronização no processo de assepsia que seja mais eficiente.

\section{Referências}

Aguiar, J. P., Yonekura, L., Macedo, S. H., Yuyama, L. K., \&Yuyama, K. (2000). Perfil nutricional das diversas formas de consumo de banana (Musa parasidíaca, variedade pacovã) da Amazonia Brasileira.

Barbosa, L. F. S., Alves, A. L., de Sousa, K. D. S. M., Neto, A. F., Cavalcante, Í. H. L., \& Vieira, J. F. (2019). Qualidade pós-colheita de banana 'Pacovan'sob diferentes condições de armazenamento. Magistra, 30, 28-36.

Batista, B. N., Raposo, N. V., \& Liberato, M. A. R. (2017). Determinação do protocolo de assepsia para reprodução in vitro de Euterpe precatoria MART. $10.5935 / 2446-4775.20170005$

Bavaresco, L. G., Pasquali, R., \& Fluminhan, A. (2017). Cultivo in vitro de explantes removidos de plantas cultivadas a campo visando à micropropagação de Eucalyptus citriodora. Periódico Eletrônico Fórum Ambiental Da Alta Paulista, 13(6). https://doi.org/10.17271/1980082713620171714

Borges, A. L. (2004). O cultivo da bananeira. L. da Silva Souza (Ed.). Embrapa Mandioca e Fruticultura. 
Darélla, M. S. (2001). Os cultivos de arroz, fumo e banana na sub-bacia do Córrego Garuva, Sombrio-SC, a utilização dos agrotóxicos e sua implicação na saúde dos trabalhadores.

da Silva, A. C. M., Dalla Costa, T. P., Costa, M. K. C., de Freitas Sia, E., \& Rodrigues, R. R. (2019). Assepsia de segmentos nodais de mini-rosa (Rosa sp.) para o estabelecimento in vitro. Journal of Biotechnology and Biodiversity, 7(1), 225-230. https://doi.org/10.20873/jbb.uft.cemaf.v7n1.silva

Effegem, C., Gontijo, A., Campanharo, A., \& Gontijo, I. (2014). Desinfestação e germinação in vitro de sementes de pimenta-do-reino (Piper nigrum L.). Enciclopédia Biosfera, 10(18).

Fernandes, D. A., Souza, R. S., \& Costa, R. B. (2011). Cultivo in vitro de teca (Tectona grandis Lf): uma revisão. Revista de Agricultura, Piracicaba, 86(1), $32-46$.

Fernandes, D. Á. (2016). Germinação e propagação in vitro de Myracrodruon urundeuva Allemão (Aroeira-do-sertão). http://ri.ufmt.br/handle/1/2426

Flori, J.E., \& Resende, G. M. (2016). Soil Chemical Attributes And Leaf Nutrients Of 'Pacovan' Banana Under Two Cover Crops. Revista Caatinga, 29(2), 290-295. https://dx.doi.org/10.1590/1983-21252016v29n204rc

Gasparotto, L., da Rocha, R. N. C., Pereira, M., Pinheiro, J., \& Lopes, R. (2019). Produtividade e viabilidade econômica do cultivo do plátano cv. pacovan em alta densidade no Amazonas. Embrapa Amazônia Ocidental-Comunicado Técnico (INFOTECA-E).

Hermímio, M., Nogueira, S. R., de Macedo, P. E. F., Soares, P. O., \& Oliveira, M. B. (2015). Produção de variedades de banana tipo Prata resistentes à Sigatoka Negra no Acre. In Embrapa Acre-Resumo em anais de congresso (ALICE). In: Congresso Regional De Pesquisa Do Estado Do Acre, Rio Branco. Embrapa.

Instituto Brasileiro de Geografia e EstatísticaNational - IBGE (2021). Produção agropecuária. https://www.ibge.gov.br/explica/producao-agropecua ria/banana/br

Machado, W., \& Zamarian, A. S. (2020). Polpa de Banana, Água de Coco e Carvão Ativado no Desenvolvimento in vitro de Lycaste sp. Ensaios e Ciência C Biológicas Agrárias e da Saúde, 24(2), 159-163. https://doi.org/10.17921/1415-6938.2020v24n2p159-163

Martínez, M. H. P., Guimarães, D. T., Silva, M. M. A., \& Ferreira, L. T. (2016). Desinfestação e germinação in vitro de sementes de mandacaru sem espinho. In Anais do Congresso Nacional de Pesquisa e Ensino em Ciências.

Matos, C. K. de, Pereira, C. E. L., Balena, L., \& Kawakami, J. (2020). Efeito da concentração de ágar no meio de cultura no desenvolvimento in vitro de plantas de batata. Research, Society and Development, 9(7), e542974571. https://doi.org/10.33448/rsd-v9i7.4571

Mezzalira, F. K., \& Kuhn, B. C. (2021, January). Padronização de um protocolo para assepsia de segmentos nodais de Phalaenopsis para clonagem in vitro. In Colloquium Agrariae (Vol. 17, No. 1). doi: 10.5747/ca.2021.v17.n1.a415.

Muniz, J. N. (2013). Micropropagação e aclimatização de Physalis peruviana e Physalis.alkekengi. http://www.cav.udesc.br/arquivos/id_ submenu/725/dissertacao_vf_.pdf

Murashige, T., \&Skoog, F. (1962). A revised medium for rapid growth and bio assays with tobacco tissue cultures. Physiologiaplantarum, 15 (3), 473-497.

Pedrotti R. L.; Bonemannmadruga A.; Govea, G. G., \& Benemann, D. (2017). Estabelecimento in vitro de Gypsophila paniculata. Apresentado na ${ }^{\circ}$ semana de inovação tecnológica da UFPEL. http://cti.ufpel.edu.br/siepe/arquivos/2017/CA_02136.pdf

Silva, C. P. D. (2015). Elaboração de biscoitos à base de Banana Pacovan (Musa paradisiaca) como opção complementar da alimentação escolar. In $I V$ Congresso de Iniciação Científica do INPA-CONIC.

Rodrigues Filho, Vagner Alves, Donato, Sérgio Luiz Rodrigues, Silva, Tânia Santos, \& Amorim, Edson Perito. (2014). Características agronômicas e ocorrência de mal-do-panamá em bananeiras tipo Pacovan. Revista Brasileira de Fruticultura, 36(2), 515-519. https://dx.doi.org/10.1590/0100-2945-379/13

Rondon, M. J. P., de Sousa, T. I., Araujo, D. A. A., Araujo, I. S., \& Fernandes, D. Á. (2019). Benefícios Do Carvão Ativado No Meio De Cultura Para Os Explantes De Banana Prata, Nanica E Terra. Connection Line-Revista Eletrônica Do UNIVAG, (21). 10.18312/connectionline.v0i21.1391

Sousa, G. C., Clemente, P. L., Isaac, V. L. R., Faria, S. P., de Siqueira Ferreira, A., \& de Cássia Campos, M. R. (2007). Contaminação microbiana na propagação in vitro de Cattleya walkeriana e Schomburgkia crispa. Revista Brasileira de Biociências, 5(S1), $405-407$.

Silva, A. C. R. (2003). Metodologia da pesquisa aplicada. Atlas. 